Article

\title{
Experimental Investigation on the DLC Film Coating Technology in Scroll Compressors of Automobile Air Conditioning
}

\author{
Zhilong He ${ }^{\circledR}$, Lantian Ji * and Ziwen Xing \\ School of Energy and Power Engineering, Xi'an Jiaotong University, Xi'an 710049, China; \\ zlhe@mail.xjtu.edu.cn (Z.H.); zwxing@mail.xjtu.edu.cn (Z.X.) \\ * Correspondence: j1t364844834@stu.xjtu.edu.cn; Tel.: +86-298-266-5996
}

Received: 17 August 2020; Accepted: 28 September 2020; Published: 1 October 2020

\begin{abstract}
The friction of the orbiting scroll leads to large power consumption and low energy efficiency of the scroll compressor. The common methods to solve this problem are high cost and a complex process. Considering special structures and operating principles to apply the coating technology on the scroll compressor is a new subject. Given the material of the orbiting scroll being aluminum alloy, the unbalanced magnetron sputtering technology for the orbiting scroll of the scroll compressor was chosen and the $\mathrm{Cr}$ transition layer was coated to enhance the bonding strength. Moreover, we innovatively performed an experiment to verify the feasibility of unbalanced magnetron sputtering film coating technology for the diamond-like carbon film coated in the scroll compressor. This article elaborates the parameter test methods of the film properties before and after experiments and the experimental system components. The results showed that the diamond-like carbon film has low coefficient and high bonding strength, which renders it a good wear-reducing effect and an excellent self-lubricating property. Due to the thin film layer and high operating temperature, the thickness should be increased to raise the abrasion resistance. The refrigeration system with the scroll compressor coated with the diamond-like carbon film can satisfy the national standard conditions with low Vickers hardness. Its performance was improved at low speed. Therefore, the unbalanced magnetron sputtering with increased $\mathrm{Cr}$ bond layer is a feasible and appropriate technology for coating diamond-like carbon film.
\end{abstract}

Keywords: diamond-like carbon film; Cr transition layer; unbalanced magnetron sputtering; scroll compressor

\section{Introduction}

Compared with other types of compressors, the wear of each part of the scroll compressor has a great impact on the reliability and performance of it [1,2]. The axial force of the orbiting scroll is shown in Figure 1. Under a normal operation condition, the forces acting on both sides of the orbiting scroll in the axial direction should be equal. According to the source of forces, forces on the scroll can be divided into the axial gas force $F_{a g}$, the axial back force $F_{a b}$, and the axial seal reaction force $F_{d}$. The axial force $F_{a}$ is the difference between the axial gas force and the axial back force. In order to obtain the axial sealing force of the orbiting scroll, the axial force is generally ensured to be negative. In practical applications, a certain axial back force is often obtained through structural design. The first method is to install a thrust bearing on the back of the orbiting scroll, such as the spherical coupling used in the scroll compressor of automobile air conditioning. This structure not only provides axial back force, but also has the function of preventing rotation. However, when the scrolls are worn, they cannot be automatically compensated, so the axial back force will be reduced. The second method is to 
apply spring force on the back of the orbiting scroll. Although this method can solve the problem of automatic compensation when the scroll is worn, when the operating conditions of the compressor change, the axial gas force and the axial sealing force will change, but the spring force is unchanged, so it cannot be realized. For automatic compensation for the best condition, the third method is to apply oil pressure on the back of the orbiting scroll. This method can reduce the friction loss between the end surface and the bottom surface due to the lubricating effect of the oil, but as the working conditions change, the oil pressure is difficult to maintain in the appropriate range, so the axial back force is also difficult to adjust to the most appropriate status. The last method is to use a back-pressure cavity structure, that is, to apply gas force on the back of the orbiting scroll. This method is to introduce the gas in the working cavity into the back-pressure cavity by opening suitable small holes on the bottom surface of the scroll, thereby generating the axial back force and the axial sealing force [3,4]. If the axial back force can be kept negative, the friction loss of the scroll will be generated. If the axial sealing force is too large, the performance and reliability of the scroll compressor will be compromised. The axial back force in scroll compressor of automobile air-conditioning is obtained by using thrust bearing, but it cannot be compensated automatically after the scroll is worn and the axial force will be reduced, which will result in the increase in internal leakage of the compressor. Therefore, the balance between seal and friction loss can be obtained by reducing the friction coefficient of the orbiting scroll surface to improve the performance of the compressor. Surface treatment is an effective and direct solution.
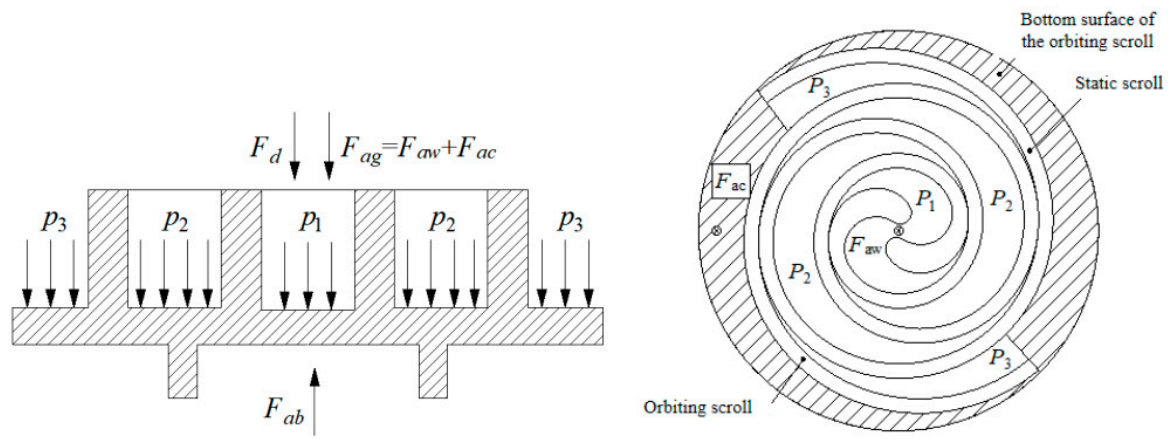

Figure 1. The schematic diagram of the axial force balance.

Among many wear resistance materials, the diamond-like carbon (DLC) film has obvious advantages because of its very low friction coefficient and wear rate. Its friction coefficient is generally below 0.20 , and the friction coefficient can even be reduced to 0.00549 by improving the preparation process, compared with other wear-resistant materials with general friction coefficient 0.35-0.70 [5-8]. Under normal circumstances, the diamond-like carbon film has a high hardness, and its hardness can reach up to $95 \mathrm{GPa}$, which is similar to the hardness of diamond. The hardness of the DLC film is mainly determined by the ratio of $\mathrm{SP}^{3}$ bonds. The larger the ratio of $\mathrm{SP}^{3}$ bonds, the higher the hardness, so the hardness of the DLC film can be adjusted $[9,10]$. When the ambient temperature is lower than $400^{\circ} \mathrm{C}$, the structure of the DLC film remains stable and the performance is good. When the ambient temperature is higher than $400{ }^{\circ} \mathrm{C}$, the hydrogen in the hydrogen-containing DLC film will escape. What is more, it will be converted into graphite when it is higher than $500{ }^{\circ} \mathrm{C}$ [11]. Therefore, the DLC film should not be used in high temperature environments. When the scroll compressor is working normally, the discharge temperature will not exceed $120^{\circ} \mathrm{C}$. When it is higher than $120^{\circ} \mathrm{C}$, the compressor's thermal protector will act and stop the compressor. Therefore, the ambient temperature will not affect the DCL film on the surface of the scroll.

$$
F_{a}=F_{a g}-F_{a b}
$$

Many researchers are devoted to the study of surface texturing progress and deposition methods of DLC films. Dongqing He et al. revealed tribological behaviors of DLC films with different 
densities fabricated by unbalanced magnetron sputter technology under dry friction and liquid lubrication conditions. The double roles of wear debris and lubricating oil reservoirs, resulting from the micro-dimples, produce lower friction and wear [12]. Chaoqian Guo et al. studied the modulation of Si on microstructure and tribomechanical properties of hydrogen-free DLC films, which was prepared by a hybrid HiPIMS (High-power Pulsed Magnetron Sputtering) and middle-frequency magnetron sputtering deposition technique [13]. For the AISI 304 stainless steel as base material, Ping Xu et al. and Liping Wang et al. used an unbalanced magnetron sputtering method, and the method combined ion plating technology and magnetron sputtering technology, respectively, to prepare the composite films containing DLC on the aluminum alloy surface to give it a better bearing capacity, wear resistance, and self-lubricating ability [14-17]. Ting Guo et al. fabricated the Ti/Al-DLC films using a unique hybrid ion beam system [18]. In medical applications, $X i$ Rao et al. used a filtered cathodic vacuum arc (FCVA) method to prepare DLC films with different $\mathrm{C}-\mathrm{C} \mathrm{SP}^{2} / \mathrm{SP}^{3}$ ratios to improve hemolysis rate and cytotoxicity level [19]. Xuexing Ding et al. applied the magnetron sputtering technology to prepare DLC film to improve the tribological behavior of the SiC dry gas seal rings [20]. Although there are plentiful research studies about the DLC film, whether it is numerical simulation or development of new composite materials, the research on DLC film in the scroll compressor to solve the friction and wear-loss problem is still insufficient due to many complicated control factors, such as suitable base materials and a reasonable coating method [21-25].

In this paper, considering the unique properties of $\mathrm{Al}$ material and the advantages of the unbalanced magnetron sputtering method-high bonding strength, easy to control thickness and suitable for large-area coating-we coated the DLC film on the surface of the orbiting scroll by unbalanced magnetron sputtering equipment with $\mathrm{Cr}$ as the transition layer to reduce its friction coefficient and thus, improve the film-substrate adhesion, wearing resistance, and the performance of the compressor. Then, the friction coefficient, hardness, thickness, surface morphology, film-substrate adhesion, composition structure analysis of the DLC film surfaces were measured and tested to verify the feasibility of the unbalanced magnetron sputter technology.

The innovation of this paper mainly focuses on the film coating technology applied in the scroll compressor to find its feasibility and advantage. Using the film coating technology to improve performance is only found in few compressors, such as the piston compressor. For example, Yan Qiang [26] et al. proposed using column arc ion coating technology to prepare TiN on the piston rod of the CNG (Compressed Natural Gas) piston compressor, which effectively improved the film-base bonding force, but the friction coefficient was relatively large. The internal structures and working progress of these two kinds of compressors are so different. Whether this technology can be applied on scroll compressors is an unknown research. For the first reason, whether coating film to improve scroll compressors can be achieved needs to be confirmed. Secondly, the technology for coating DLC film is a subject much to be studied. Thirdly, the film properties in scroll compressors are influenced by so many factors like the controlling parameters, the index of the device, the manipulation and so on. Therefore, the film properties need to be tested. This will involve material-industry-related information. Solving the above problems is the main innovation point. Our results could provide a theoretical basis and experimental evidence for optimizing the surface treatment of the orbiting scroll and improving the performance of scroll compressors.

\section{Experimental Methods}

Experiments were carried out to prepare the DLC film, test the characteristic parameters of the DLC film, and measure the performance parameters of the scroll compressor. Friction coefficient, hardness, thickness, surface morphology, film-substrate adhesion, and composition structure of the DLC film are the main testing parameters. The power and volumetric efficiency reflect the performance of the compressor. By analyzing and comparing the above parameters, the rationality and feasibility can be obtained. In order to demonstrate the performance characteristics of the DLC film, a sample that had been plated with an anodic oxide film was selected as the control object. 


\subsection{The Surface Treatment of the Orbiting Scroll}

Diamond-like carbon film is a kind of metastable amorphous material in the form of $\mathrm{SP}^{2}$ bonds and $\mathrm{SP}^{3}$ bonds. As a result, DLC film has unique properties which cannot be replaced by diamond and graphite. In general, the magnetron sputtering coating equipment uses an equilibrium magnetic field to control the plasma to form a stable and continuous plasma region. Additionally, magnetron sputtering coating technology has the advantages of a wide range of target sources, uniform and dense film formation, and high bonding strength $[23,27,28]$. However, if the coating is placed in the plasma region, the ion current density and energy of the coating will affect the structure and performance of the coating. In addition, if the shape of the coating is more complex, the shadow problem on the film surface will be more serious [29]. To solve these problems, an unbalanced magnetron sputtering (UBMS) technology is proposed.

The UBMS working principle is shown in Figure 2. It enhances the magnetic field of the $\mathrm{N}$ pole on both sides or weakens the magnetic field of the intermediate $\mathrm{S}$ pole such that the $\mathrm{S}$ pole and $\mathrm{N}$ pole form a transverse magnetic field on the surface of the target to ensure that the secondary electrons deposited can be effectively constrained and stably discharged by changing the distribution of magnetic fields via balanced magnetron sputtering. Further, the other part of the electrons escapes from the target surface through the longitudinal magnetic field of the $\mathrm{N}$ pole and enters the coating area [30].

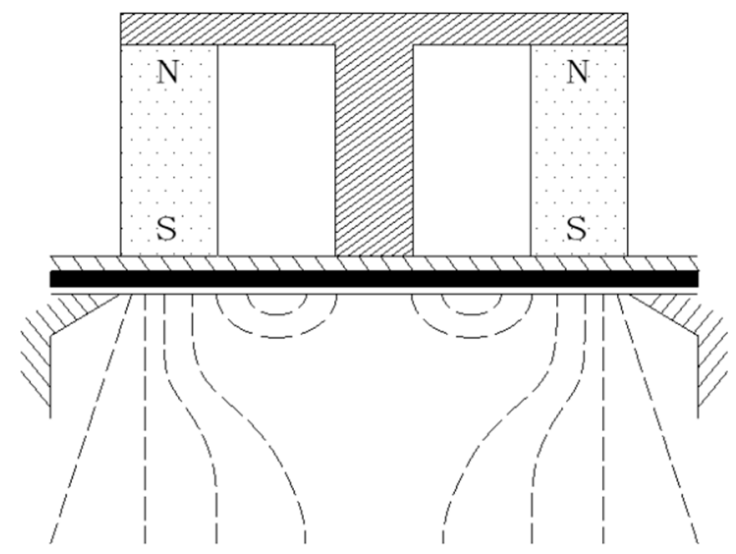

Figure 2. Schematic diagram of unbalanced magnetron sputtering principle.

After the preparation of the orbiting scroll specimens, the grease and residual dirt on the surface of the orbiting scroll was removed to make the film layer easier to fit the substrate material. The acetone and the ethanol were used as the cleaning medium in ultrasonic cleaning machine to remove remaining impurities on the metal surface. Then, in this unbalanced closed magnetic field magnetron sputtering surface treatment progress, the glow discharge cleaning method was applied to remove the carbon and hydrocarbon impurities. The cleaning process was filled with appropriate inert gas argon, and the working pressure was adjusted to $10 \mathrm{~Pa}$. After dehydration and the drying progress, the specimen was put into a vacuum chamber $(0.0027 \mathrm{~Pa})$. Next, the fiber laser marking machine was used to generate ionization power to heat and etch the surface of the sample to increase the bonding force between the film and the surface of the sample. Finally, the $\mathrm{Cr}$ transition layer was coated on the substrate surface to enhance the bonding force, and then the DLC film was coated on the Cr layer through opening the magnetron target successively (coating time $75 \mathrm{~min}$ ).

\subsection{Characteristic Parameters Testing of the DLC Film}

\subsubsection{Wearing Coefficient}

The friction and wearing experiments are critical for the analysis of friction performance of solid surface. Two samples and a ball of $5 \mathrm{~mm}$ diameter made of $\mathrm{Al}_{2} \mathrm{O}_{3}$ were rubbed for 10 thousand 
revolutions under certain loads to measure the change of the wearing coefficient on the friction testing machine.

\subsubsection{Thickness}

There are usually three ways to express the film thickness: shape thickness, mass thickness, physical thickness. The thickness here refers to the shape thickness, that is, the distance between the substrate surface and the film surface. In practical measurement, the surface of the film is rough, and there are many impurities in it. An appropriate measurement method should be selected to characterize the thickness of the film. The thickness of the anodic oxide film in this experiment was measured by indirect measurement method with the spherical pit thickness measuring instrument. The thickness of the DLC film was measured by direct measurement using a scanning electron microscope (SEM).

\subsubsection{Microhardness}

The hardness of the orbiting scroll is not only closely related to its service life but also the efficiency of compressors, so it is one of the most important parameters to evaluate the quality of the orbiting scroll. A microhardness tester (Vickers indenter) was used to test the hardness of the material. In order to avoid the deformation of the body in the testing process, an appropriate load should be used. In this testing experiment, the MH-VK (Microhardness-Vickers and Knuckle indenter) microhardness test system was used to measure the microhardness. We put $50 \mathrm{~g}$ loads on the surfaces of the two samples, respectively, with Vickers indenter and measured the diagonal length of indentations after loading, holding, and unloading to calculate the microhardness of samples.

\subsubsection{Film-Substrate Adhesion}

The film-substrate adhesion refers to the external force required to peel the film from the substrate, which indicates the bonding strength between the film and the substrate. In general, the smaller the difference in the physical and chemical properties between the film and the substrate, the higher the adhesion. Besides, the adhesion is also affected by the factors such as the preparation process, the transition layer, and the film composition. In this paper, the film-substrate adhesion of the anodic oxide film and the DLC film was measured by scratch method which is a quantitative measuring method. First, we used the scratch instrument to leave scratch marks with different loads on the surfaces of the two samples, as shown in Figure 3. In this figure, the left one is the sample coated with the anodic oxide film and the right one with the DLC film. The loads on the surface of the anodic oxide film from left to right are $60 \mathrm{~N}, 70 \mathrm{~N}, 80 \mathrm{~N}$, and $90 \mathrm{~N}$, respectively, and on the surface with the DLC film from left to right are $40 \mathrm{~N}, 60 \mathrm{~N}, 70 \mathrm{~N}, 80 \mathrm{~N}$, and $90 \mathrm{~N}$. Then the peeling point of the film substrate was found under the scanning electron microscope.

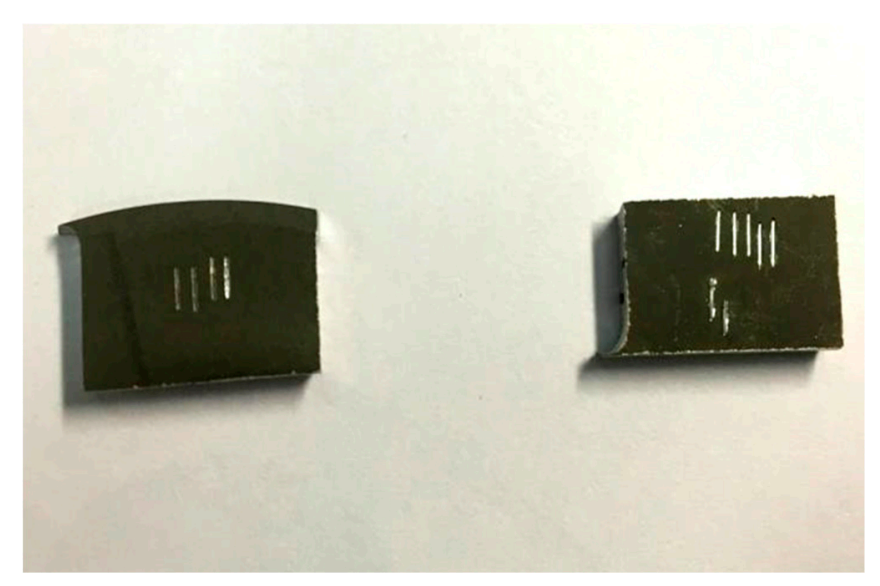

Figure 3. The samples with the anodic oxide film (AOF) and the diamond-like carbon (DLC) film for measuring the adhesion. 


\subsubsection{Surface Morphology}

At present, the most common tool to study the surface morphology of materials is the scanning electron microscope (SEM). It can provide surface morphology images clearly and intuitively and give quantitative or semi-quantitative surface composition analysis results. The principle of scanning electron microscopy is that the surface of the sample is bombarded with a very narrow electron beam to motivate signals, such as the secondary electrons and transmitted electrons on the surface of the sample, which can be analyzed to observe the surface morphology of the sample. The resolution ratio of SEM can reach 5-10 nm, and the magnification times can be adjusted from several times to 1 million times.

\subsubsection{Composition Structure}

X-ray diffraction (XRD) is usually used to detect the structure and composition of the film surface and determine the crystal plane of solid surface. If the surface crystal composition of the two materials is different, their XRD spectrogram will show obvious differences in angle position, diffraction peak number, and shape. Therefore, the phase composition of the sample can be determined by analyzing the X-ray diffraction pattern on the surface of the experimental sample. For amorphous substances on the surface, because of the irregular arrangement of atoms in space, there will be no obvious diffraction peak in the diffraction spectrum. Therefore, the phase composition of samples was analyzed by the D/max-3A X-ray diffraction instrument.

\subsection{Performance Parameters Measuring of the Scroll Compressor}

In order to compare and analyze the performance of DLC film in the scroll compressor, a performance experiment was carried out. This performance test bench for automobile air-conditioning compressors was based on the GB/T 5773-2016 Volumetric Refrigerant Compressor Performance Test Method. The test bench was debugged according to the standard operating conditions in GB/T 21360-2008 Refrigeration Compressors for Automobile Air-Conditioning to ensure the accuracy of the compressor performance test.

The principle of this experiment is close to a simple automobile refrigeration and air conditioning system. Figure 4 is the schematic diagram of experimental progresses. The refrigerant is R134a. The evaporator and condenser in this experiment all use plate heat exchangers. As an ideal equipment for high-efficiency heat exchange, the plate heat exchanger has two forms: assembled and brazed. The evaporator and condenser used in the experiment are all brazed. The compressors used in the experiment are two scroll refrigeration compressors for fully enclosed cars, the model is ATC-086-F10, and the driving mode is pulley. The basic parameters of the compressors are shown in Table 1. Figure 5 shows the real scroll compressor used in experiments.

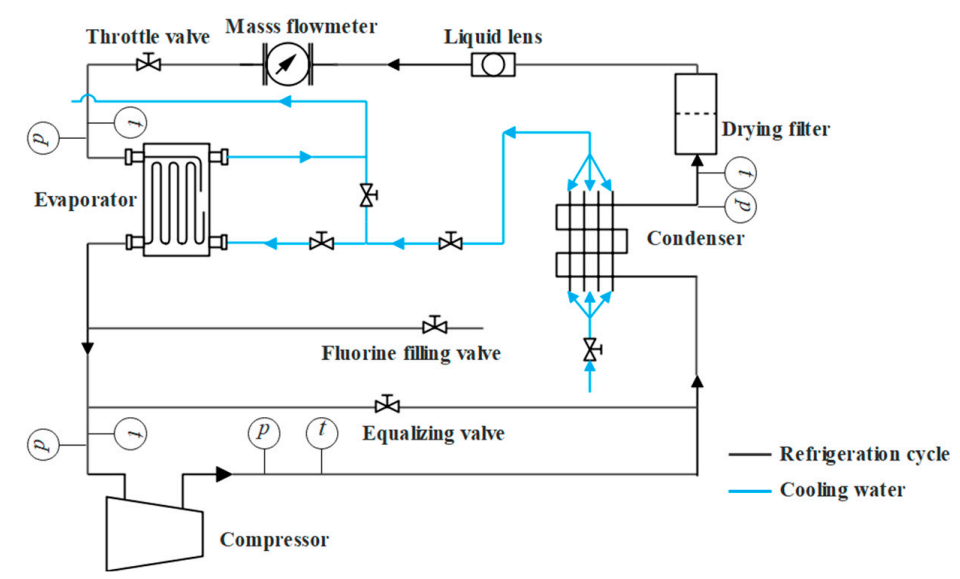

Figure 4. The performance experiment flow diagram. 
Table 1. The basic parameters of the compressors.

\begin{tabular}{ccccc}
\hline Model & Displacement/cc & Power/V & Refrigerant & Lubricating Oil \\
\hline ATC-086-F10 & 86 & 12 & R134a & PAG56 \\
\hline
\end{tabular}

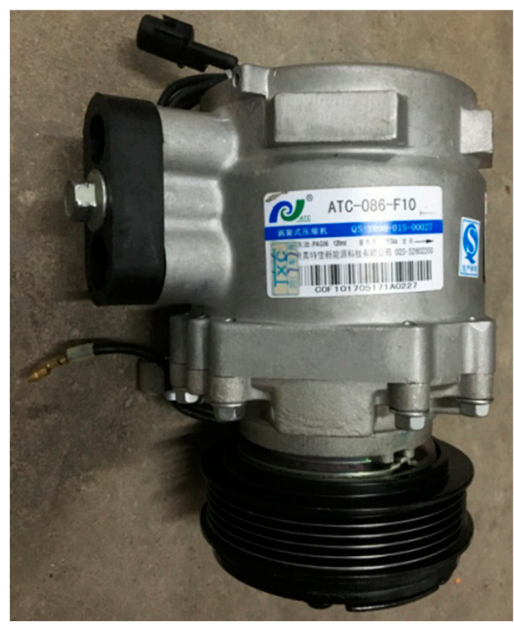

Figure 5. The scroll compressor used in experiments.

Due to the large resistance of the plate heat exchanger, if an internally balanced thermal expansion valve is used, it will affect the accuracy of the superheat. Therefore, this experiment used an externally balanced thermal expansion valve. As the tube diameter of the mass flow meter was small and easy to be blocked, the filter drier was installed before the mass flow meter to remove mechanical impurities (such as metal chips and oxide scale) in the refrigerant and to adsorb moisture in the refrigerant. We installed a sight glass before the flow meter to observe whether there was a gaseous working fluid. Plus, this experiment uses the refrigerant liquid flowmeter method, and the flowmeter is a Coriolis mass flowmeter, as shown in Figure 6. The temperature measurement uses a Pt100 thermal resistance temperature sensor with an accuracy of class $\mathrm{A}$, and the temperature measurement range is $-50-200{ }^{\circ} \mathrm{C}$, which meets the requirements of use. The temperature of each measuring point is collected in real time with a temperature inspection instrument, and the measurement error is $\pm 0.5 \%$ FS (Full Scale) \pm 1 word, and the additional cold junction compensation error is $\pm 1{ }^{\circ} \mathrm{C}$. The accuracy of the suction pressure gauge is 0.4 , and the range is 0 to $1.6 \mathrm{MPa}$. The discharge pressure gauge accuracy is 1.6 , the range is 0 to $4 \mathrm{MPa}$, and it is resistant to high temperature and vibration. The refrigerant charge amount is determined according to the actual operating conditions, and its value is obtained through the reading of the electronic scale, and the scale value of the electronic scale is $1 \mathrm{~g}$.

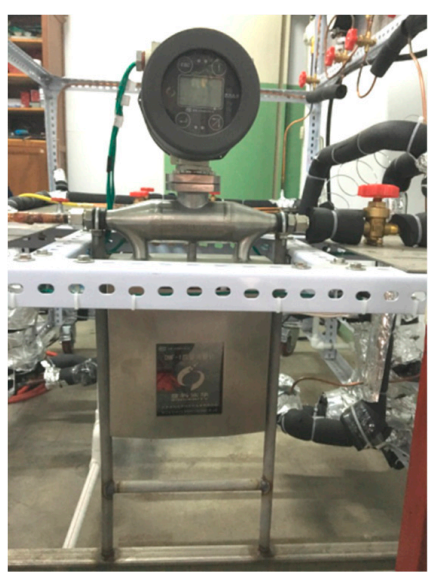

Figure 6. The Coriolis mass flowmeter. 
The condensation pressure and the degree of subcooling were adjusted by the cooling water flow rate whose temperature was $16^{\circ} \mathrm{C}$. The evaporation temperature (or pressure) is adjusted by the heat exchange on the evaporation side. The evaporation temperature is adjusted by adjusting the water flow on the evaporation side. The superheat at the outlet of the evaporator is adjusted by the thermal expansion valve. The condensing temperature (or pressure) and the degree of subcooling are adjusted by the heat exchange on the condensing side. In the experiment, the condensing pressure is adjusted by adjusting the water flow on the condensing side. Since the filling of refrigerant and the oil volume in the system can influence experimental results, the optimal values are $1210 \mathrm{~g}$ and $217.8 \mathrm{~g}$, respectively, after repeated debugging. The data of performance experiment were recorded after keeping steady for more than $0.5 \mathrm{~h}$. The refrigeration capacity was tested according to the refrigerant liquid flow meter method, and the power was collected by a digital electric parameter measuring instrument. After that, we debugged and collected data on the experimental test bench under standard working conditions, then processed and analyzed the collected data. The experimental working conditions are shown in Tables 2 and 3.

Table 2. Variable rotational speed experimental operation conditions.

\begin{tabular}{ccccc}
\hline Numbering & Speed $/ \mathbf{r} \cdot \mathbf{m i n}^{-\mathbf{1}}$ & $\begin{array}{c}\text { Evaporation } \\
\text { Temperature } /{ }^{\circ} \mathbf{C}\end{array}$ & $\begin{array}{c}\text { Condensation } \\
\text { Temperature } /{ }^{\circ} \mathbf{C}\end{array}$ & Superheat $/{ }^{\circ} \mathbf{C}$ \\
\hline Condition 1 & 1200 & -1 & 57.9 & $10 \pm 0.5$ \\
Condition 2 & 1400 & -1 & 57.9 & $10 \pm 0.5$ \\
Condition 3 & 1600 & -1 & 57.9 & $10 \pm 0.5$ \\
Condition 4 & 1800 & -1 & 57.9 & $10 \pm 0.5$ \\
Condition 5 & 2100 & -1 & 57.9 & $10 \pm 0.5$ \\
\hline
\end{tabular}

Table 3. Variable pressure ratio experimental operation conditions.

\begin{tabular}{ccccc}
\hline Numbering & Pressure Ratio & $\begin{array}{c}\text { Evaporation } \\
\text { Temperature } /{ }^{\circ} \mathbf{C}\end{array}$ & $\begin{array}{c}\text { Condensation } \\
\text { Temperature } /{ }^{\circ} \mathbf{C}\end{array}$ & Superheat $/{ }^{\circ} \mathbf{C}$ \\
\hline Condition 1 & 3.601 & -1 & 40 & $10 \pm 0.5$ \\
Condition 2 & 4.108 & -1 & 45 & $10 \pm 0.5$ \\
Condition 3 & 4.668 & -1 & 50 & $10 \pm 0.5$ \\
Condition 4 & 5.283 & -1 & 55 & $10 \pm 0.5$ \\
Condition 5 & 6.389 & -1 & 63 & $10 \pm 0.5$ \\
\hline
\end{tabular}

\section{Results and Discussion}

Figure 7 shows friction coefficient curves and test samples. At the initial stage of wear, the friction coefficient of the two samples increases rapidly because the $\mathrm{Al}_{2} \mathrm{O}_{3}$ ball is polished by the surface of the samples. The friction coefficient of the sample coated with DLC film is gradually stabilized after 10,000 rotations but with the anodic oxide film it is not, showing an increasing trend. The friction coefficient with the anodic oxide film is much larger than that with the DLC film. As shown in Figure 7b, the surface of the sample with the anodic oxide film has a chip-grinding phenomenon. The surface scratch of the sample with the DLC film is relatively shallow and smooth. It proves that the DLC film has a good wear-reducing effect and an excellent self-lubricating property. 


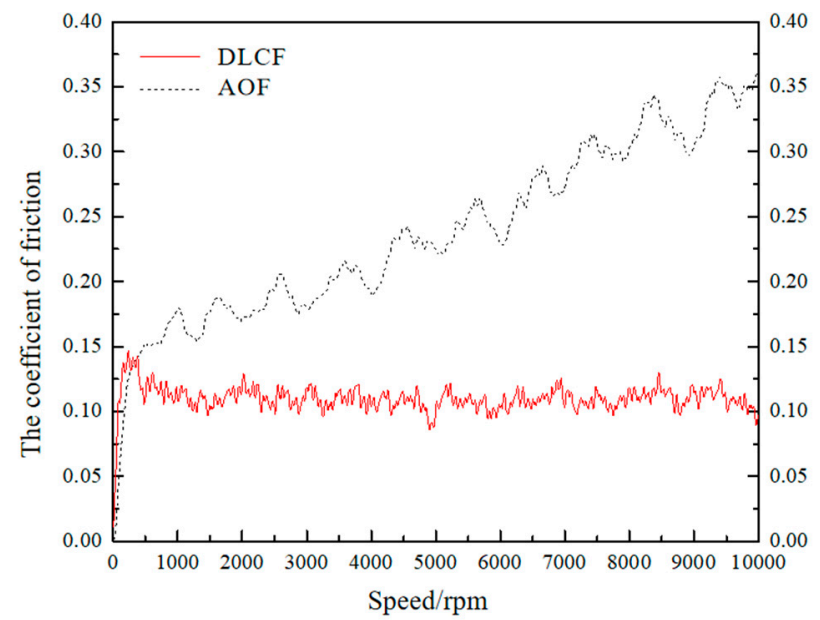

(a)

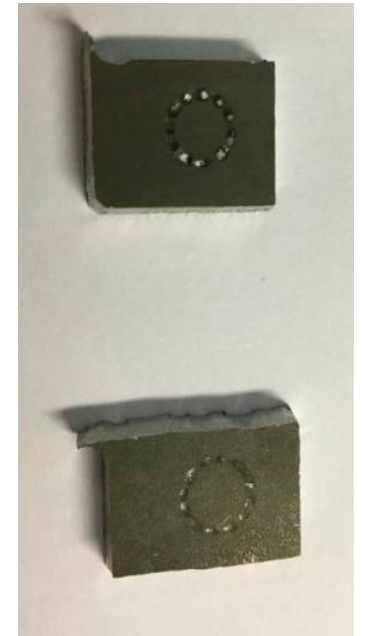

(b)

Figure 7. The friction coefficient curve and the test samples: (a) the friction coefficient curve; (b) the test samples.

The thicknesses of anodic oxide film and DLC film are $4 \mu \mathrm{m}$ and $0.73 \mu \mathrm{m}$, respectively, which means the DLC film is better than the anodic oxide film. Figure 8 shows the section topography of the DLC film. The hardness of the anodic oxide film and DLC film are 254.1 HV and 206.7 HV, respectively. The Vickers hardness of the sample with DLC film is lower than that with anodic oxide film. The thickness and the hardness are not related directly. The main reason why the hardness is lower is that there are fewer $\mathrm{SP}^{3}$ bonds and more $\mathrm{SP}^{2}$ bonds, which makes the DLC film have a property close to graphite. Furthermore, the hardness of DLC film is related to the working temperature. When the working temperature is increased, the hardness will be decreased.

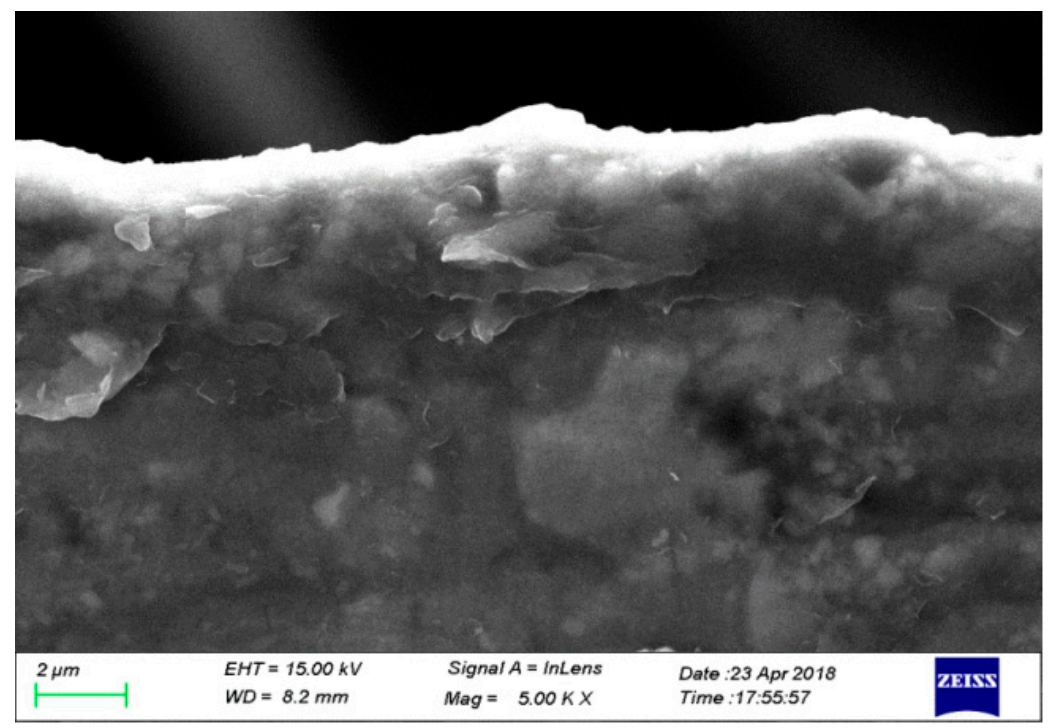

Figure 8. Section topography of the DLC film.

Figure 9a,b shows the surface of anodic oxide film under $60 \mathrm{~N}$ loads and the DLC film under $90 \mathrm{~N}$ loads, respectively. As can be seen from Figure 9, the anodic oxide film is peeling off when the load is $60 \mathrm{~N}$, but no peeling point is found on the surface of the DLC film when the load is $90 \mathrm{~N}$, which proves that the bonding strength of the DLC film is much higher than that of the anodic oxide film. 


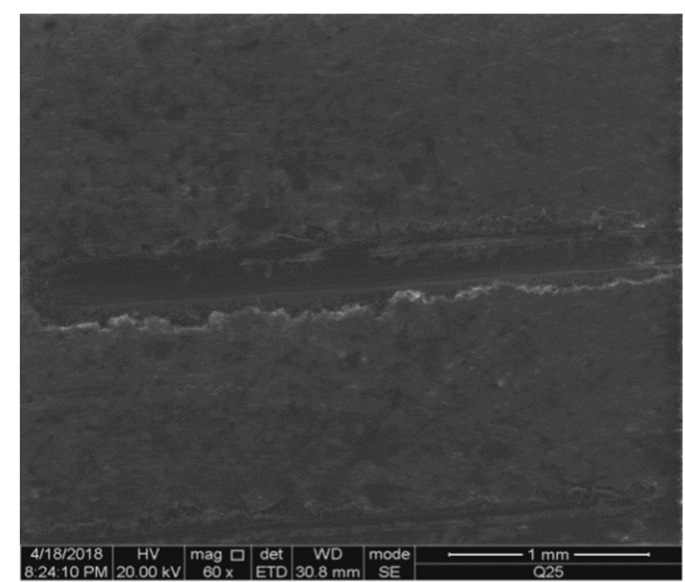

(a)

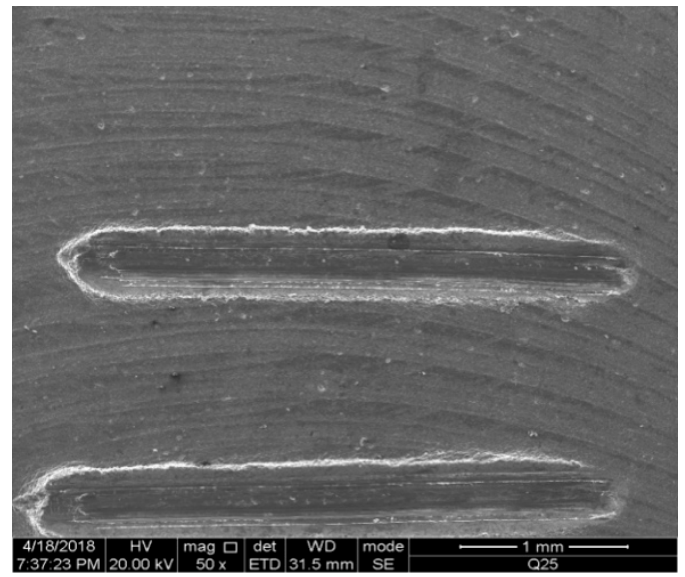

(b)

Figure 9. The surface of samples for measuring the adhesion: (a) the surface of the anodic oxide film/60 N; (b) the surface of the DLC film/90 N.

Figures 10 and 11 show the surface morphology with the SEM. Although the surface of the anodic oxide film (AOF) has been treated, the surface smoothness is poor and there are many pores. These defects could result in a poor film-substrate adhesion and high friction coefficient of the anodic oxide film. However, the surface of the sample coated with DLC film is flat and smooth. The crystalline grain of the DLC film is uniformly and compactly distributed on the surface of the sample with good coating quality, which eliminates the surface defects of the orbiting scroll. In addition, there are no obvious bubbles around the crystalline grain, which ensures the bonding strength between the DLC film and the sample body.

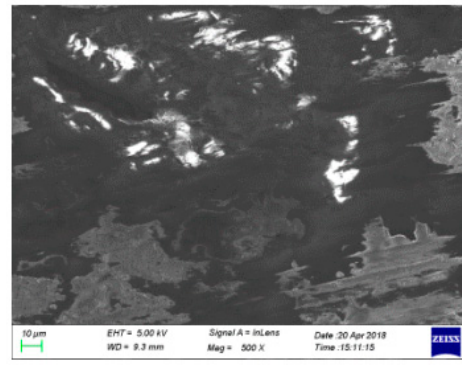

(a)

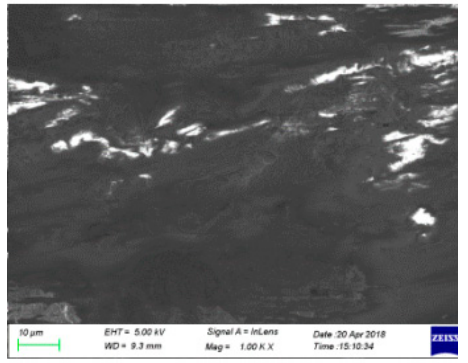

(b)

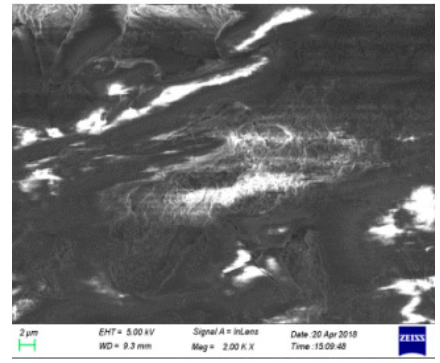

(c)

Figure 10. The surface morphology of AOF samples with the SEM: (a) 500 times; (b) 1000 times; (c) 2000 times.

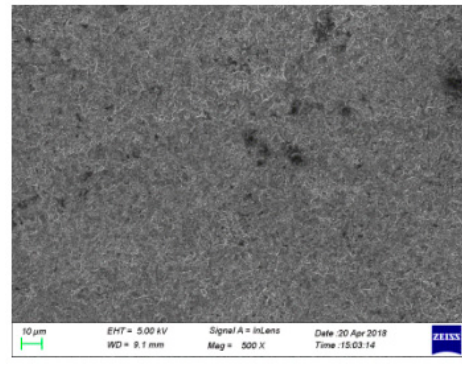

(a)

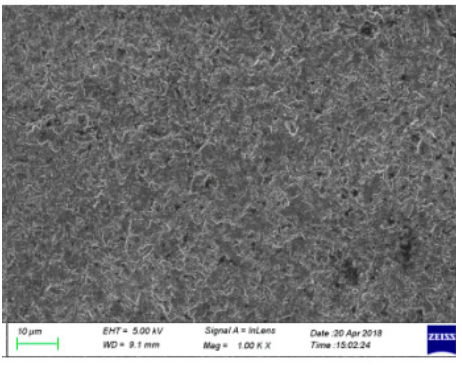

(b)

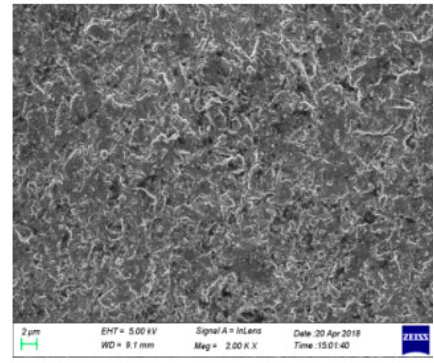

(c)

Figure 11. The surface morphology of DLC samples with the SEM: (a) 500 times; (b) 1000 times; (c) 2000 times. 
The X-ray diffraction spectrum of the anodic oxide film and the DLC film is shown in Figure 12. It shows that there is no significant difference in the XRD spectrum between the anodic oxide film surface and the DLC film surface. The DLC film is mainly characterized by the diffraction peak of the substrate. Under the usual diffraction conditions, the penetration depth is about dozens of microns, while the thickness of the anodic oxide film is only $0.73 \mu \mathrm{m}$ in amorphous state, resulting in no carbon diffraction peak. In order to further analyze the composition of the films, the surface composition and content of the two samples were analyzed by energy dispersive spectrometer (EDS). Table 4 shows the surface element content and percentage of DLC film. The results show that the carbon content in the DLC film is very low (only $5.90 \%$ ), and the $\mathrm{Cr}$ content is much higher (26.17\%). This is because the film layer of the DLC film is thin, and the results detected by EDS mainly are the element content and percentage of the substrate. In order to further analyze whether there are carbon elements on the surface of the DLC film, the energy spectrum analysis of the DLC film section was carried out (Figure 13). The carbon content maximum value is relatively high (about $54.92 \%$ ). Based on the previous analysis, the surface substance composition of the DLC film can be determined to be carbon and chromium. Moreover, it is verified that the reason why the micro Vickers hardness of the DLC film is lower than that of the anodic oxide film is fewer $\mathrm{SP}^{3}$ bonds and more $\mathrm{SP}^{2}$ bonds, which makes the property of the DLC film close to graphite.

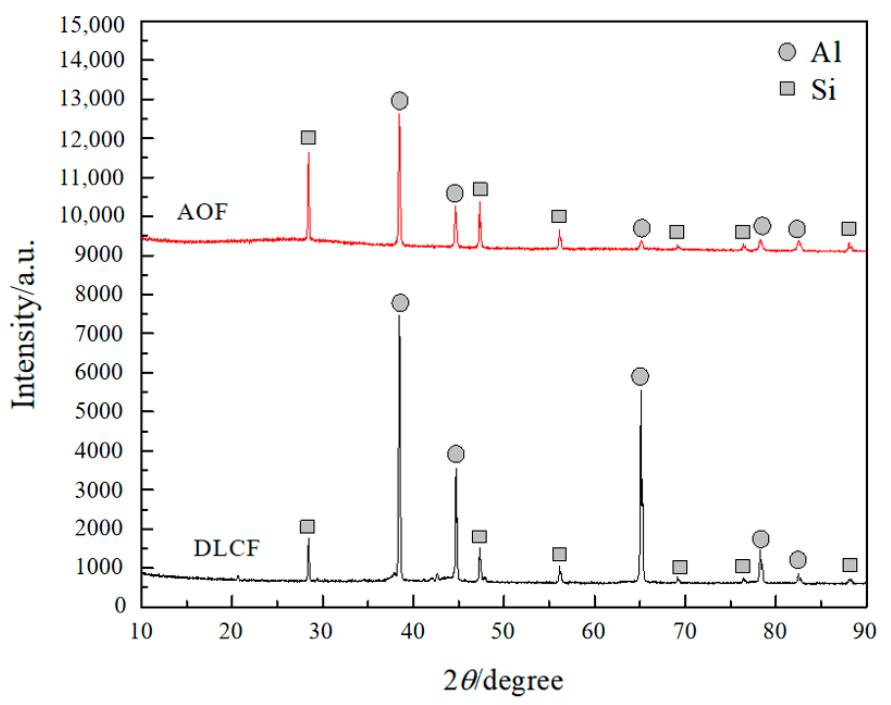

Figure 12. The X-ray diffraction spectrum of the AOF and the DLC film.

Table 4. Variable pressure ratio experimental operation conditions.

\begin{tabular}{cccccc}
\hline Element & Line & Apparent Concentration & k Ratio & wt.\% & Standard Sample Label \\
\hline $\mathrm{C}$ & $\mathrm{K}$ & 1.41 & 0.01413 & 5.90 & Simple substance \\
$\mathrm{N}$ & $\mathrm{K}$ & 13.92 & 0.09613 & 23.60 & $\mathrm{BN}$ \\
$\mathrm{Al}$ & $\mathrm{K}$ & 50.33 & 0.45608 & 42.17 & $\mathrm{Al}_{2} \mathrm{O}_{3}$ \\
$\mathrm{Si}$ & $\mathrm{K}$ & 1.42 & 0.01304 & 1.50 & $\mathrm{SiO}_{2}$ \\
$\mathrm{Cr}$ & $\mathrm{K}$ & 32.03 & 0.32035 & 26.17 & $\mathrm{Cr}$ \\
$\mathrm{Cu}$ & $\mathrm{L}$ & 0.46 & 0.00460 & 0.66 & Simple substance \\
Total & & & & 100.00 & \\
\hline
\end{tabular}




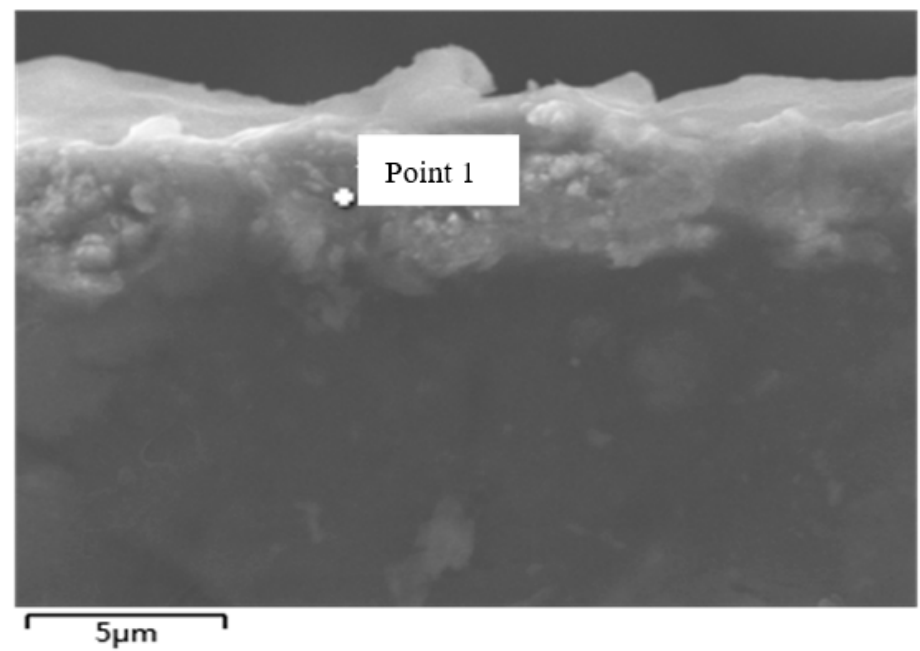

Figure 13. The section surface energy spectrum of DLC film.

Volumetric efficiency and power consumption are effective parameters to evaluate the compressor performance (Figures 14 and 15). It can be noticed that the power of the scroll compressor coated with DLC film increases by $13.6 \%$ with the rotating speed increasing by $200 \mathrm{rpm}$ and $14.0 \%$ with the pressure ratio increasing by an average 0.56 . The volumetric efficiency decreases by 0.0382 with the rotating speed increasing by $200 \mathrm{rpm}$ and 0.00377 with the pressure ratio increasing by an average 0.56. That is because that the thickness of DLC film is too thin to make the internal leakage of the compressor increase and the volumetric efficiency decrease. It means that the thickness of $0.73 \mu \mathrm{m}$ should be increased. Many research studies show that the thickness should be in the range $2.5-5 \mu \mathrm{m}$. As they said, if the thickness is too low, the wear life will drop sharply. When the rotating speed is high, the leakage and wear cannot be ensured to make the machine run normally. If the thickness is too high, the intake and discharge space will be affected, and energy consumption will increase. Whether this phenomenon occurs in the same way in scroll compressors remains to be studied. In addition, because the Vickers hardness of DLC film is lowered by this UBMS technology, the wear of the orbiting scroll is more serious, which makes the power consumption of the compressor and internal leakage increase. It is a key research point for future adjustments and improvements.
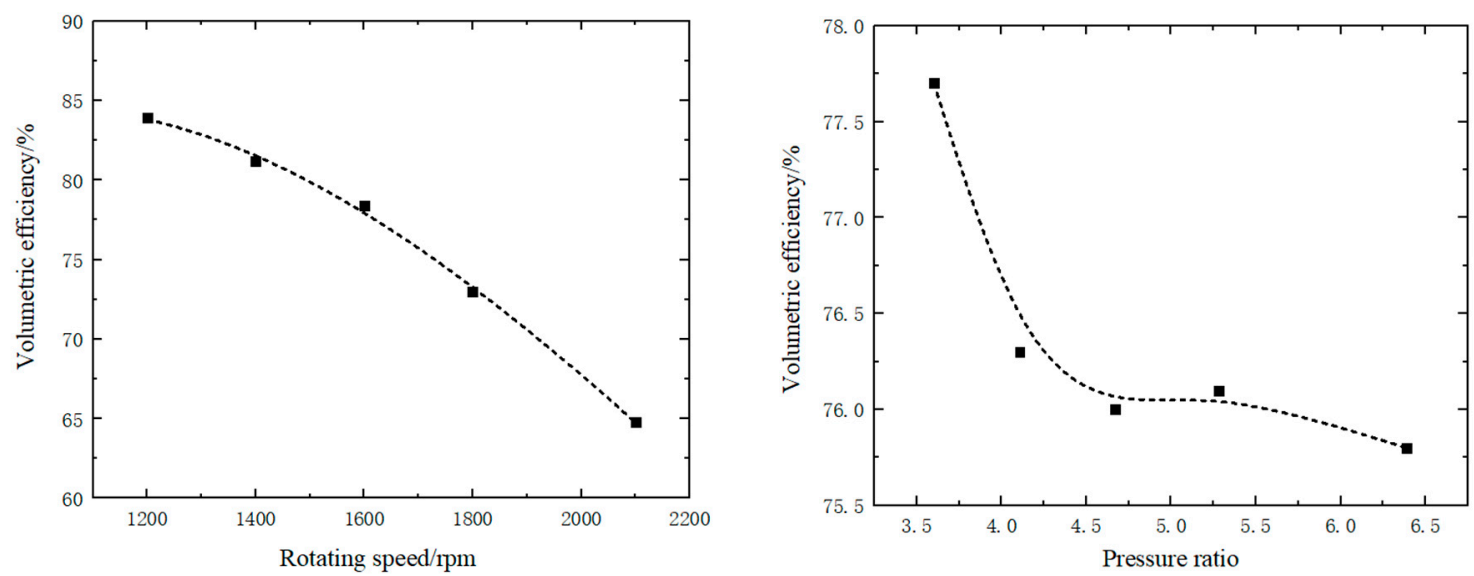

Figure 14. Volumetric efficiency of the scroll compressor coated with DLC film. 

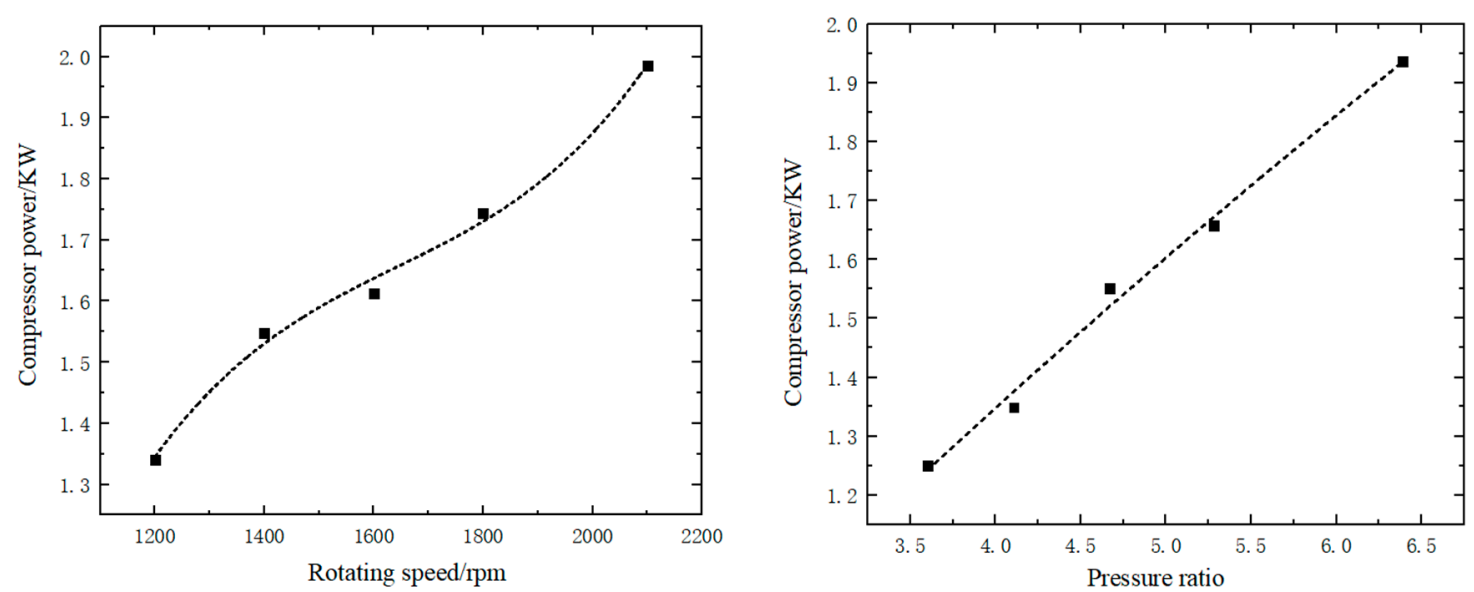

Figure 15. Power consumption of the scroll compressor coated with DLC film.

After operating through the experiments, we tested the properties of the DLC film again. There are corresponding scratches and wear on the surface of the compressor scroll, especially the suction and discharge ends. The scratches on the surface of the scroll are due to impurities mixed in the system. Therefore, samples were taken at the suction and discharge ends of the compressor, and the surface morphology of the samples was observed through an electron microscope.

The test results are shown in the Figures 16 and 17. It can be found that the surface of the orbiting scroll has fatigue wear mainly due to delamination. Since the discharge end is the area where the scroll is most stressed and thermally deformed, the friction and wear are the most serious. Therefore, combined with the surface morphology of the scroll after operation, it can be concluded that the reason why the performance of the compressor is good at low speeds is the flat surface of the DLC film and low friction coefficient, which reduces the flow-resistance loss of the working fluid. When the speed is high, the main reason for its performance degradation is that under a high rotation speed, the low hardness and thickness of the orbiting scroll results in increased wear and obvious internal leakage.

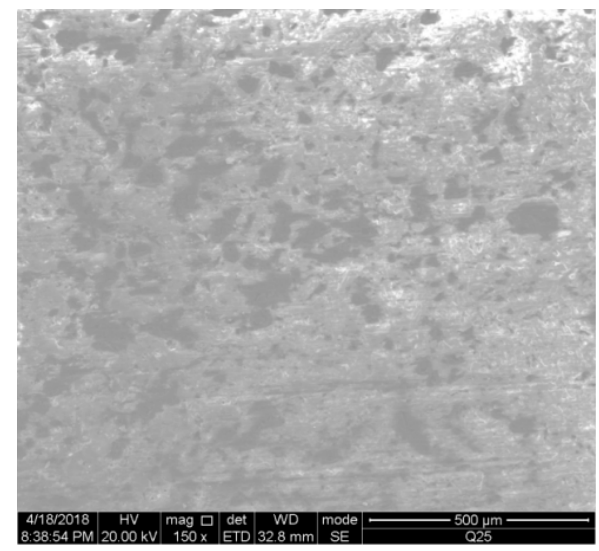

(a)

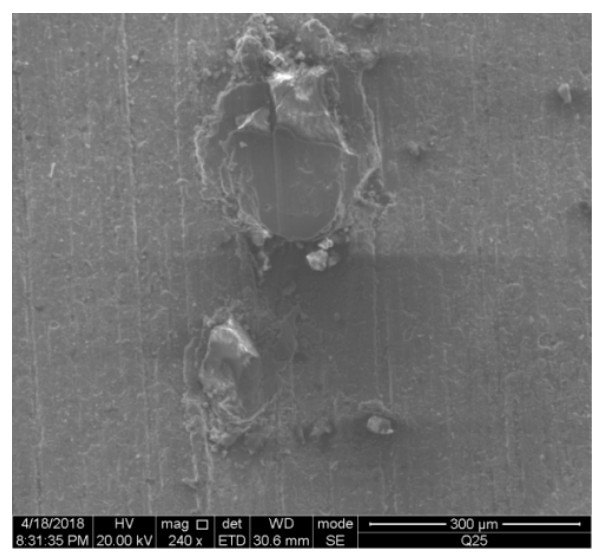

(b)

Figure 16. The suction end surface topography of the orbiting scroll after the compressor with DLC film is running: (a) 150 times; (b) 240 times. 


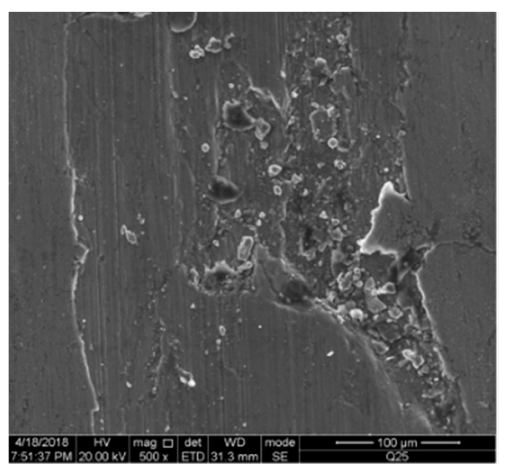

(a)

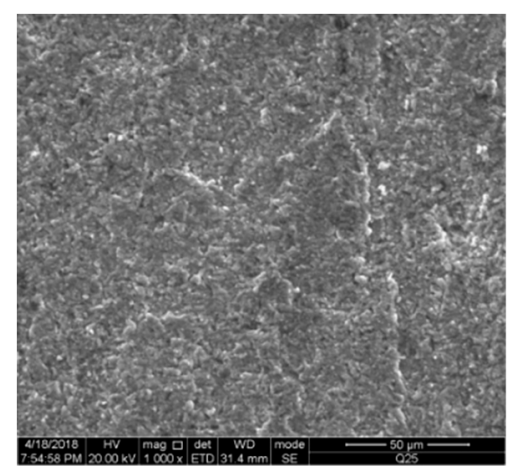

(b)

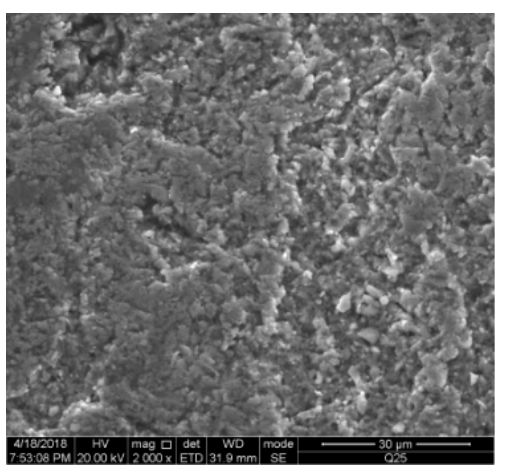

(c)

Figure 17. The suction end surface topography of the orbiting scroll after the compressor with DLC film is running: (a) 500 times; (b) 1000 times; (c) 2000 times.

\section{Conclusions}

In this paper, we mainly studied the film coating technology of the DLC film for the orbiting scroll of scroll compressors in an automobile air conditioning system to reduce its friction coefficient and improve film-substrate adhesion, wear resistance, and performance of the compressor. Considering that the material of the orbiting scroll is aluminum alloy, we proposed the unbalanced magnetron sputter technology to coat the DLC film on the surface of the orbiting scroll, analyzed the properties of the DLC film, compared the properties of the DLC film with those of the anodic oxide film as controls for the scroll compressor, and designed performance experiments to verify the reliability and feasibility of the unbalanced magnetron sputter film coating technology in scroll compressors.

The friction coefficient with the DLC film is much smaller than that with the anodic oxide film, which makes the DLC film have a good wear-reducing effect and an excellent self-lubricating property. The thickness of the anodic oxide film and the DLC film is $4 \mu \mathrm{m}$ and $0.73 \mu \mathrm{m}$, respectively. The Vickers hardness of the sample with the DLC film is lower than that with the anodic oxide film, and the bonding strength of the DLC film is much higher than that of the anodic oxide film. The surface of the sample coated with DLC film is flat and smooth, which eliminates the surface defects of the orbiting scroll. The surface substance composition of the DLC film was determined to be carbon and chromium. It is also verified that the reason why the micro Vickers hardness of the DLC film is lower than that of the anodic oxide film is fewer $\mathrm{SP}^{3}$ bonds and more $\mathrm{SP}^{2}$ bonds, which makes the property of the DLC film close to graphite. The refrigeration system with the scroll compressors coated with the DLC film can meet the national standards, indicating the surface treatment technology is suitable and appropriate. The DLC film can improve the film-substrate adhesion, wear resistance, and the performance of the compressor. The unbalanced magnetron sputter technology and increasing $\mathrm{Cr}$ bond layer are feasible and appropriate for coating DLC film on the orbiting scroll of scroll compressors. Furthermore, through the performance experiments, the power of the scroll compressor coated with DLC film increases and the volumetric efficiency decreases with the rotating speed and pressure ratio increasing. The thickness of DLC film should be increased to 3-4 $\mu \mathrm{m}$. Finally, the Vickers hardness of DLC film is lowered by this UBMS technology, which is a key development direction for future research.

The optimized scheme of the unbalanced magnetron sputtering technology proposed in this paper to prepare DLC film on the surface of aluminum alloy to improve the wear resistance of the scroll, not only reduces the friction coefficient of the scroll surface, but also improves the bonding force of the film base, which can effectively solve the problem of large friction loss of the scroll compressor. Scroll compressors have been widely used in a variety of refrigeration applications. As the largest energy-consuming component in the system, the ability to use this more energy-saving, environmentally friendly, low cost, safe and reliable method to solve key problems will undoubtedly lead to the further expansion of the material industry and machinery industry. The idea of this solution can not only be applied to scroll compressors but can be applied to power machinery such as hydrogen 
pumps based on the experimental data parameters, because, at present, in addition to fuel vehicles, fuel cell electric vehicles are also research hotspots and key development projects. The solution can reduce mechanical burden in the automotive industry with higher safety requirements and is one of the technical solutions that are worthy of reference. In the meantime, the experimental data can be used as the training database for compressor fault diagnosis.

Author Contributions: Investigation, Z.H.; resources, Z.H.; data curation, L.J.; writing-original draft preparation, L.J.; supervision, Z.X. All authors have read and agreed to the published version of the manuscript.

Funding: This research received no external funding.

Conflicts of Interest: The authors declare no conflict of interest.

\section{Nomenclature}

$\begin{array}{ll}F_{a g} & \text { Axial gas force/N } \\ F_{a b} & \text { Axial back force/N } \\ F_{d} & \text { Axial seal reaction force/N } \\ F_{a} & \text { Axial force/N } \\ F_{a w} & \text { Component force of the gas force perpendicular to the scroll bottom surface/N } \\ F_{a c} & \text { Component force of the gas force perpendicular to the scroll side surface/ } \mathrm{N} \\ P & \text { Pressure/Pa }\end{array}$

\section{References}

1. Li, C.; Jiao, Y.; Zhang, J. Fractal Prediction Model of Friction Force of Orbiting and Static Scroll End Face Friction Pair. J. Chem. Ind. 2012, 8, 2524-2530.

2. Ma, S.X. Research on Friction and Lubrication of Scroll Compressor; Lanzhou University of Technology: Lanzhou, China, 2007.

3. Zhao, M.; Yu, S.R.; Li, C. Analysis of Orbiting Scroll Overturning for Scroll Compressor. Appl. Mech. Mater. 2012, 226, 576-579. [CrossRef]

4. Jeong, B.S. Friction Characteristics of the Tip Seal in a Scroll Compressor. J. Korean Soc. Tribol. Lubr. Eng. 2014, 30, 370-377.

5. Zheng, W.T. Thin Film Materials and Thin Film Technology; Chemical Industry Press: Beijing, China, 2003.

6. Donnet, C. Advanced Solid Lubricant Coatings for High Vacuum Environment. Surf. Coat. Technol. 1996, 80, 151-156. [CrossRef]

7. Zeng, Q.F.; Dong, G.N.; Luo, L. High Temperature Friction Characteristics and Thermodynamic Analysis of Diamond-like Carbon Films. J. Mater. Heat Treat. 2014, 35, 151-155.

8. Liao, Y.; Fan, X.W.; Xie, L.C. Application of Wear-resistant and Self-lubricating DLC Coating on Air Source Heat Pump Water Heater Compressor. Refrig. Air Cond. 2015, 15, 58-60.

9. Werner, M.; Locher, R. Growth and application of undoped and doped diamond films. Rep. Prog. Phys. 1998, 12, 1665. [CrossRef]

10. Yuan, Z.H.; Deng, Q.S. Preparation, performance and application of diamond-like carbon film. J. Mater. Sci. Eng. 1994, 4, 32-38.

11. Er, K.H.; So, M.G. Thermal stability of reactive sputtered silicon-doped diamond-like carbon films. J. Ceram. Process. Res. 2013, 1, 134-138.

12. He, D.Q.; He, C.; Li, W.S. Tribological Behaviors of In-situ Textured DLC Films under Dry and Lubricated Conditions. Appl. Surf. Sci. 2020, 525, 1-9. [CrossRef]

13. Guo, C.Q.; Lin, S.S.; Gao, D. Modulation of Si on Microstructure and Tribo-mechanical Properties of Hydrogen-free DLC Films Prepared by Magnetron Sputtering. Appl. Surf. Sci. 2020, 509, 1-9. [CrossRef]

14. Xu, P.; Cao, X.Q.; Zhang, M.L.; Yue, W.; Zhang, G.A. Friction and Wear Behaviors of Different DLC Films Sliding against SiC and Si3N4 Balls under High Relative Humidity. Diam. Relat. Mater. 2020, 108, 1-9. [CrossRef]

15. Wang, L.P.; Wan, S.H.; Wang, S.C.; Wood, R.J.K.; Xue, Q.J. Gradient DLC-Based Nanocomposite Coatings as a Solution to Improve Tribological Performance of Aluminum Alloy. Tribol. Lett. 2010, 38, 155-160. [CrossRef] 
16. Xia, L.F.; Yan, Z.H.; Liao, J.X. Effects of intermediate layers on the tribological behavior of DLC coated 2024 aluminum alloy. Wear 2004, 257, 599-605.

17. Wang, Z.S. Study on Multi-Layer Film on Aluminum Matrix Composites; Dalian University of Technology: Dalian, China, 2010.

18. Guo, T.T.; Kong, C.C.; Li, X.W. Microstructure and Mechanical Properties of Ti/Al Co-doped DLC Films: Dependence on Sputtering Current, Source Gas, and Substrate Bias. Appl. Surf. Sci. 2017, 410, 51-59. [CrossRef]

19. Rao, X.; Yang, J.H.; Chen, Z.L. Tuning C-C sp2/sp3 Ratio of DLC Films in FCVA System for Biomedical Application. Bioact. Mater. 2020, 5, 192-200. [CrossRef]

20. Ding, X.X.; Chen, D.L.; Zhang, W.Z.; Yu, S.R. Experiment of Frictional Vibration Performance of the Micro-texture of DLC Thin Film with Dry Gas Seal Rings. Tribol. Int. 2020, 147, 1-10. [CrossRef]

21. Dai, D.H.; Liu, M.; Yu, Z.M. Modern Surface Technology of Thin Film and Coating; Central South University Press: Changsha, China, 2008.

22. Chen, M.; Sun, F.H.; Zhang, Z.M. CVD diamond coating technologies and application in cutting abrasive materials. Key Eng. Mater. 2001, 196, 193. [CrossRef]

23. Shi, Y.L.; Yan, F.Y. Thin Film Technology and Thin Film Materials; Chemical Industry Press: Beijing, China, 2001.

24. Jia, J. Preparation and progress of nanocrystalline thin films by sputtering. Semicond. Technol. 2004, 29, 70-73.

25. Wang, Y.C. Present situation and Development of vacuum coating Technology. Mod. Instrum. Med. Treat. 2000, 6, 1-4.

26. Yan, Q.; Tao, W.; Liang, Z. Study on the performance of TiN wear-resistant coating on CNG compressor piston rod. Compress. Technol. 2015, 1, 34-37.

27. Sun, Y.J.; Ma, L.; Qi, H.J. Preparation of waterproof and moisture-permeable fabric by magnetron sputtering method. Polym. Mater. Sci. Eng. 2003, 4, 188-191.

28. Bräuer, G.; Szyszka, B.; Vergöhl, M.; Bandorf, R. Magnetron sputtering-Milestones of 30 years. Vacuum 2010, 12, 1354-1359. [CrossRef]

29. Xu, J.Q.; Hang, L.X.; Hui, Y.X. The characteristics of unbalanced magnetron sputtering diamond-like carbon film. J. Vac. Sci. Technol. 2005, 2, 134-137.

30. Dong, Q.; Fan, Y.D. Unbalanced Magnetron Sputtering and Its Application. J. Vac. Sci. Technol. 1996, 1, 51-57. 